\title{
Community advocacy groups as a means to address the social environment of female sex workers: a case study in Andhra Pradesh, India
}

\author{
Swarup Punyam, ${ }^{1}$ Renuka Somanatha Pullikalu, ${ }^{1}$ Ram Manohar Mishra, ${ }^{2}$ \\ Prashanth Sandri, ${ }^{1}$ Balakrishna Prasad Mutupuru, ${ }^{1}$ Suresh Babu Kokku, ${ }^{1}$ \\ Prabhakar Parimi ${ }^{1}$
}

${ }^{1}$ India HIV/AIDS Alliance,

Hyderabad, India

${ }^{2}$ Population Council, New Delhi, India

\section{Correspondence to} Dr Swarup Punyam, India HIV/AIDS Alliance, Sarovar Center, 5-9-22, Secretariat Road, Hyderabad 500063 , Andhra Pradesh, India; pswarup@allianceindia.org

Accepted 14 March 2012 Published Online First 11 April 2012

\section{UNLOCKA}

This paper is freely available online under the BMJ Journals unlocked scheme, see http:// jech.bmi.com/site/about/ unlocked.xhtml

\begin{abstract}
Background To examine the association between the presence of community advocacy groups (CAGs) and female sex workers' (FSWs) access to social entitlements and outcomes of police advocacy.

Methods Data were used from a cross-sectional survey conducted in 2010-2011 among 1986 FSWs and 104 NGO outreach workers from five districts of Andhra Pradesh. FSWs were recruited using a probability-based sampling from 104 primary sampling units (PSUs). A PSU is a geographical area covered by one outreach worker and is expected to have an active CAG as per community mobilisation efforts. The presence of active CAGs was defined as the presence of an active committee or advocacy group in the area (PSU). Outcome indicators included acquisition of different social entitlements and measures of police response as reported by FSWs. Multivariate linear and logistic regression analyses were used to examine the associations.
\end{abstract}

Results Areas with active CAGs compared with their counterparts had a significantly higher mean number of FSWs linked to ration cards (12.8 vs 6.8; $p<0.01$ ), bank accounts (9.3 vs $5.9 ; p=0.05)$ and health insurance (13.1 vs $7.0 ; p=0.02$ ). A significantly higher percentage of FSWs from areas with active CAGs as compared with others reported that the police treat them more fairly now than a year before $(79.7 \%$ vs $70.3 \% ; p<0.05)$ and the police explained the reasons for arrest when arrested the last time $(95.7 \%$ vs $87 \%$; $p<0.05)$.

Conclusion FSWs from areas with active CAGs were more likely to access certain social entitlements and to receive a fair response from the police, highlighting the contributions of CAGs in community mobilisation.

\section{INTRODUCTION}

In India currently about 2.3 million people are infected with HIV. ${ }^{1}$ The epidemic in the country is predominantly heterosexual and is assumed to be driven through unprotected sex with female sex workers (FSWs). ${ }^{2}$ HIV prevalence among Indian FSWs is about 15 times higher than the general populations. ${ }^{3}{ }^{4}$ Studies indicate that FSWs are at high risk for HIV and are highly vulnerable to various forms of violence, abuse and stigma. ${ }^{5}$ They are often deprived of social benefits and entitlements that are otherwise accessed by women in the general population. ${ }^{6-10}$ Violence experienced by FSWs and their limited access to social entitlements may contribute to HIV risk-taking behaviours in various ways. ${ }^{7-12}$ For example, forced sex is usually unprotected and can result in injuries that increase the transmission of HIV. ${ }^{13}$ Similarly, barriers to accessing services such as bank accounts increase FSWs' vulnerability to theft as well as debt from informal sources such as money lenders, madams and pimps that reduce their negotiation ability in sexual exchange. ${ }^{11}$

The role of violence and lack of access to social entitlements in increasing the vulnerability of FSWs have been documented in the state of Andhra Pradesh, which is one of the six HIV highprevalence states in India. ${ }^{1}$ A recent communitybased survey in eight districts of Andhra Pradesh found HIV prevalence among FSWs ranging from $6.5 \%$ to $23.3 \%{ }^{14}$ FSWs from the state experience substantially high rates of physical and sexual violence, which is positively correlated with economic insecurity. ${ }^{10}$ Another study has concluded that unstable housing among FSWs is linked to experience of sexual and physical violence and their risky sexual behaviours. ${ }^{2}$

Recognising the importance of such structural barriers, researchers have argued that HIV prevention programmes must go beyond the peer-led intervention approach to address the complex social, cultural, political and economic vulnerabilities faced by marginalised population groups most at risk of acquiring HIV infection. ${ }^{9}{ }^{15-18}$ One of the strategies to address these structural barriers is through the development of community-based organisations (CBOs), in which vulnerable populations, especially FSWs and men who have sex with $\mathrm{men} /$ transgenders, participate in group formation and work towards reducing the vulnerability of marginalised communities o 9 19-21 An essential component of these structural interventions is to reduce the stigma, abuse and violence directed at sex workers, particularly incidents perpetrated by the police, goondas (abusive men) and sexual partners/ clients. ${ }^{19}$ Another important component is to provide organised support to FSWs to obtain their social and economic entitlements, such as ration cards, bank accounts and plots of land for housing (L Ramachandar, unpublished, 2011). ${ }^{9}$ A specific advocacy structure within $\mathrm{CBO}$ s has also been recommended to address the social vulnerabilities faced by FSWs and to create an enabling environment. ${ }^{22-24}$ An example of such structural intervention is the setting up of an active advocacy group which works at different levels to influence 
policy makers and state administrative agencies to benefit marginalised communities. ${ }^{23}$ However, less is known about the scale-up strategy in development and implementation of an active advocacy group and their relative benefits. This paper describes the development of a scaled-up community advocacy group (CAG) system and its effect on related programme outcomes: increasing FSWs' access to social entitlements and fair response from the police (less police arrests, police informing FSWs of the reasons for arrest and perceived fair treatment by the police in general). These outcomes were examined by comparing the FSWs from areas where CAGs were active (functional) and areas where there were no active CAGs.

\section{Description of the programme: the CAG}

The HIV prevention programme considered in this paper covered a total of 14 districts in Andhra Pradesh. CAGs were initiated in 2006 as part of the development of CBOs and other components of the programme. The development of $\mathrm{CBO}$ s in Andhra Pradesh, as in many other states of India, has drawn lessons from community mobilisation in the Sonagachi project in Kolkata, which has reported the increased empowerment of FSWs. ${ }^{9} 21$

During the early phases of the structural intervention programme, it was observed on many occasions that FSWs could not use condoms or access clinical services due to factors such as threats from the police and local goondas and fear of identification as a sex worker. The experience of violence and abuse also contributed to low self-esteem, thus undermining the possibility of effective HIV prevention. ${ }^{25}$ Surveys carried out among FSWs in the early phases of the programme showed that most sex workers had low expectations concerning the usefulness of group action. 'Overall only one in four FSWs strongly believed that participating in a peer group could empower them .... Similarly, perceptions of social support among the entire sample were low...'26

This evidence led the programme to develop an organised system of advocacy, which involved the participation of FSWs. Training of FSWs in communication and advocacy skills and building their knowledge of legal rights and related information began on a pilot basis in four districts in November 2006. Initially, CAGs focused on sensitising the police, local goondas, auto rickshaw/taxi drivers and others to reduce violence among FSWs. After six months of intervention, interaction with FSWs revealed that the advocacy activities were leading to a significant reduction in the abuse of FSWs and increase in their access to social entitlements. The types of social entitlements accessed in the programme and the key stakeholders approached for these are detailed in table 1.

\section{Structure and functioning of the CAG system}

At places where FSWs solicit clients (referred to as hotspots), small groups of FSWs, locally known as community action teams, were formed to address FSWs' problems, including abuse, violence and lack of access to social entitlements. These groups of FSWs were assisted to form CAGs at the mandal (subdistrict) and the NGO (multiple mandal) levels. Community action teams from different hotspots coordinated advocacy needs with CAGs at the mandal and NGO levels. Meetings of NGO-level CAGs were held once a month to address difficult cases and review the progress of advocacy activities at the mandal and local levels. Every NGO-level team was provided a crisis telephone number, which a sex worker could call in the event of violence. The functioning of the community action team was similar to the crisis response system established within community mobilisation programmes in other settings. ${ }^{24}$ The structure and functioning of CAGs are detailed in figure 1.

\section{METHODS}

The functioning of the CAG system was regularly monitored using two data streams: (1) the monitoring and information system (MIS) and (2) the Behavioural Tracking Survey. The MIS captured the number of violence cases documented, the number of FSWs who applied for social entitlements and the number of police personnel who attended advocacy meetings. The Behavioural Tracking Survey is a cross-sectional survey conducted among FSWs and outreach workers who work with the NGOs to provide programme services to FSWs.

This paper utilises data primarily from the Behavioural Tracking Survey conducted in 2010-2011 in five districts of Andhra Pradesh, namely Khammam, Warangal, Kurnool, Medak and Ananthapur. The objectives of the survey were to monitor the key components of the HIV prevention programme such as community mobilisation, access to social entitlements, violence and abuse, treatment seeking for sexually transmitted infection and the formation and functioning of advocacy groups. The study districts were purposively selected to include areas where the HIV prevention programme is being implemented, and behavioural and biological surveys have not been conducted prior to the Behavioural Tracking Survey. A sample size of 400 FSWs was calculated for each district based on the prevalence of consistent condom use and expected level of change with each unit change in the degree of community mobilisation.

In order to prepare the sampling frame for the selection of FSWs from each hotspot, a rapid mapping exercise was conducted by the data collection agency using key informant

Table 1 Type of social entitlements accessed in the programme and key stakeholders approached

\begin{tabular}{ll}
\hline Type of social entitlement & Definition \\
\hline Ration card & Allows an individual or a family living below the poverty line to access \\
& certain essential commodities like rice, sugar and kerosene at subsidised prices \\
& Used as a proof of identity \\
& In some cases makes the card holder eligible to obtain other benefits such as \\
& membership in a state-sponsored health insurance scheme and cooking gas \\
& at a reduced price \\
Voter identity card & Provides evidence of an individual's civic identity \\
& Gives a person the right to vote in elections \\
Bank account & Essential for accessing many benefits from government programmes \\
Free education for children & Allows children of school-going age to access free education services \\
Health insurance & A state-sponsored community health insurance scheme for BLP families \\
(Rajiv Aarogyasri) & Entitles card holders to access medical services from corporate hospitals \\
House site pattas (certificates) & Poor houseless persons are given government wasteland for housing
\end{tabular}




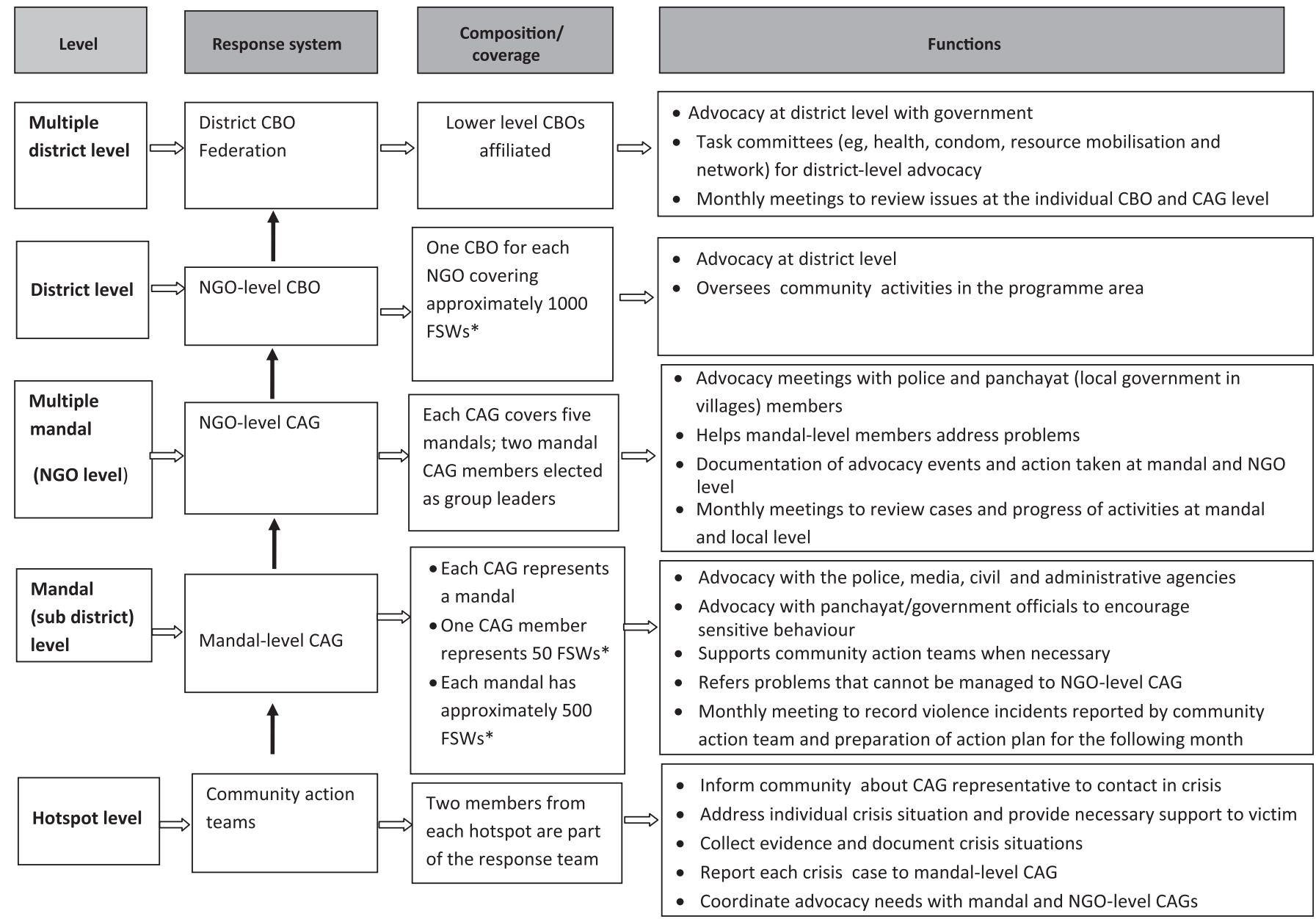

Figure 1 Structure of the community advocacy system. *Approximate values are presented which may vary depending upon the size of female sex workers' population in the area.

interviews with community members, police staff and social workers in the area to validate the existing list of hotspots that were originally developed by the programme-implementing agency. The hotspots were grouped into two categories: (1) nonpublic place hotspots (brothels, hotels, lodges, roadside eating establishments and homes) and (2) public place hotspots (streets, market areas, highways and cinema halls). For each non-public place hotspot, data were gathered on the number of FSWs available at the hotspot. For each public place hotspot, data were gathered on the number of FSWs at the hotspot, segregated by the time slots when they gathered for sex work (eg, 9:00-13:00; 15:00-19:00, etc). Primary sampling units (PSUs) were defined as the geographical area covered by an NGO outreach worker for programme implementation, which usually consists of approximately 250 FSWs. Thus, each PSU consisted of several public place and non-public place hotspots.

FSWs in each PSU were recruited through a two-stage sampling procedure. In the first stage, a fixed number of hotspots within each PSU were selected using the proportion to population size procedure. The number of interviews to be conducted in each PSU was proportionally allocated in accordance with its share in the total population of FSWs in the district. The number of interviews to be conducted from each PSU was further proportionately disaggregated between public place and non-public place hotspots. A conventional cluster sampling approach was used to select non-public place hotspots, whereas time-location cluster sampling was used to select public place hotspots. In time-location cluster sampling, a hotspot was replicated multiple times to form a time-location cluster for each time slot when FSWs congregate at the hotspot. Details of the time-location cluster sampling approach are available elsewhere. ${ }^{27}$ In the second stage, FSWs were randomly selected within each selected hotspot. Data on socio-demographics, incidents of violence, behaviour of the police and access to different social entitlements were collected through face-to-face interviews using a structured questionnaire.

Of the total 2389 FSWs approached, 403 either refused to participate in the study or withdrew during the course of the interview. This resulted in a total analytical sample of 1986 FSWs from 104 PSUs. The response rate was 83.1\%. The main reasons for non-participation were phone calls or interruption from clients, heavy rain and objections from pimps/brokers or madams.

In addition to interviews with FSWs from the 104 PSUs, all the 104 outreach workers from these PSUs were interviewed face-to-face using a semistructured questionnaire to assess: whether FSWs in their area perceived the need for a particular social entitlement such as ration cards, voter identity cards, bank accounts, free education for children, health insurance and other (eg, housing pattas (certificates) and cooking gas connections); whether a cell group/individual had been assigned to facilitate access to the particular entitlement and the number of FSWs who had been linked to a particular entitlement in the past 1 year. Of the 104 outreach workers interviewed, 98 were FSWs. 
All interviews were conducted by trained researchers with verbal and written skills in Telugu, the local language of Andhra Pradesh. All the researchers had a Bachelor's degree in sociology or statistics. The survey instrument was developed in English and translated into Telugu. The translated forms were reviewed by study investigators who were fluent in both English and Telugu. The interview schedule was then pretested in communities that were similar to the survey sites. Field staff checked the data immediately after the interviews to ensure accuracy and completion of questionnaires. Field supervisors reviewed the data on the same day and survey forms were sent every week to the data management team for data entry. A user written computer programme in CSPro (V.4.0) was used for double data entry by trained data entry officers.

\section{Ethical considerations}

The overall study design and questionnaires were reviewed and approved by the institutional review boards of Family Health International and the Karnataka Health Promotion Trust. A comprehensive informed consent process was followed; respondents were informed about the study, including the duration of the interview (approximately $30 \mathrm{~min}$ ), and their queries addressed before verbal consent was taken. For ethical reasons, only those FSWs who were at least 18 years of age were interviewed. To protect confidentiality and respect privacy, all questionnaires were anonymous and interviews were conducted in a private or public location depending on the FSW's preference. A small room was hired in each PSU where interviews were conducted in privacy. In areas where it was not possible to hire a room, public locations were identified such as parks or isolated corner roads where others would not be able to listen to the interview. Participants were not given any monetary compensation for their time in the study but were provided information on HIV services available in the area.

\section{Key measures}

\section{Socio-demographic characteristics of FSWs}

The socio-demographic characteristics of FSWs considered in this paper were current age, any formal schooling (no, yes), marital status (currently married, not currently married), typology of sex work (brothel-based, home-based, public placebased) and duration of sex work. Any formal schooling was defined as the ability to both read and write. Typology of sex work was derived on the basis of primary place of solicitation.

\section{CAG status}

The key independent variable in the present study was the status of the CAG (non-active, active) in each PSU. For each social entitlement considered in the paper, PSUs were defined to have an active CAG if at least one individual or a group was assigned to facilitate access to that particular social entitlement. Any active CAG was defined as the presence of any type of advocacy group in the PSU (no, yes).

\section{Acquisition of social entitlements}

FSWs were asked whether or not they have the following social entitlements: ration card, voter identity card, bank account and free education for children. Those who reported having a social entitlement were further asked when they had acquired the particular entitlement. Based on responses to these questions, a variable measuring duration of acquisition of the social entitlement with the following three categories was computed: not acquired, acquired for more than 36 months and acquired within the last 36 months. The cut-off point of 36 months was chosen because CAGs were formed approximately 36 months prior to the survey.

\section{Behaviour of the police with FSWs}

The behaviour of the police with FSWs was measured by the following indicators collected by interviewing FSWs: ever arrested by the police (no, yes), whether the police explained reasons when arrested last time (no, yes), whether the police had informed at least one friend or relative about the arrest when arrested last time (no, yes), whether ever interacted with the police (no, yes) and whether FSWs perceive that the police treat them more fairly now than they did a year before (no, yes).

\section{Statistical analyses}

The association between CAG status and acquisition of social entitlements (as per the programme-monitoring data) in the past 1 year was examined by using multivariate linear regression models with the number of FSWs linked to different social entitlements in the PSUs as the continuous outcome measure. Separate linear regression models were used to estimate the regression coefficient $(\beta)$ and corresponding SEs for CAG status for different social entitlements. The number of FSWs registered in the HIV prevention programme in PSUs was considered as a covariate in each regression model. To supplement the observed association between CAG status and number of FSWs linked to different social entitlements in each PSU, data sets collected from FSWs and outreach workers were merged. The percentage of FSWs in categories of duration of acquisition (not acquired, acquired for more than 36 months, acquired within last 36 months) for different social entitlements was compared for PSUs with and without active CAGs. Significance of the differences in the percentages was tested using the $Z$ test statistic. The merged data were also used to examine the association between CAG status and police behaviour with FSWs.

Table 2 FSWs' interaction with the police and reported experiences of abuse in five district of Andhra Pradesh, Behavioural Tracking Survey, 2010-2011

\begin{tabular}{|c|c|c|c|c|c|c|}
\hline $\begin{array}{l}\text { Interaction with the police and experience } \\
\text { of abuse }\end{array}$ & $\begin{array}{l}\text { Ananthapur } \\
(\mathrm{N}=400)\end{array}$ & $\begin{array}{l}\text { Medak } \\
(N=400)\end{array}$ & $\begin{array}{l}\text { Khammam } \\
(\mathrm{N}=396)\end{array}$ & $\begin{array}{l}\text { Warangal } \\
(\mathrm{N}=390)\end{array}$ & $\begin{array}{l}\text { Kurnool } \\
(\mathrm{N}=400)\end{array}$ & $\begin{array}{l}\text { Total } \\
(N=1986)\end{array}$ \\
\hline Ever arrested by the police $(\%)^{* * *}$ & 19.8 & 2.9 & 5.7 & 7.6 & 20.3 & 14.9 \\
\hline Police explained reasons for arrest $†(\%)^{* * *}$ & 97.2 & 75.1 & 73.0 & 89.9 & 91.3 & 93.8 \\
\hline $\begin{array}{l}\text { Police informed at least one friend or relative } \\
\text { about the arrest } \dagger(\%)^{* *}\end{array}$ & 49.2 & 30.2 & 49.5 & 23.1 & 32.1 & 44.6 \\
\hline Ever interacted with the police $(\%)^{* * *}$ & 80.5 & 39.2 & 39.5 & 66.4 & 63.2 & 66.2 \\
\hline $\begin{array}{l}\text { Feels that the police treat FSWs more fairly } \\
\text { now than they did } 1 \text { year before } \neq(\%)^{* * *}\end{array}$ & 83.3 & 59.5 & 59.0 & 76.6 & 74.9 & 77.9 \\
\hline
\end{tabular}

${ }^{* *} \mathrm{p}<0.01 ;{ }^{* * *} \mathrm{p}<0.001$. Significance of the differences in the percentages across districts was tested using $\chi^{2}$ test.

†Among FSWs who had ever been arrested refers to FSWs' experience when they were arrested last time.

$\ddagger$ Among FSWs who had ever interacted with the police.

FSW, female sex worker; $N$, number of cases. 
Multiple multivariate logistic regression models were used to estimate adjusted ORs and the corresponding 95\% CIs for different indicators of police behaviour with FSWs. The sociodemographic characteristics of FSWs were used as covariates in the logistic regression models. Data were analysed using the statistical software STATA (V.11).

\section{RESULTS}

In the CAG programme, over 500 FSWs were trained in the basic components of legal literacy and communication skills to conduct advocacy sessions with the police and other stakeholders such as the media. They also received training on meeting government officials to negotiate on acquisition of social entitlements. The MIS records show that during January to December 2010, CAG members met with over 500 police personnel to sensitise them and presented information on 175 crisis cases in various print and electronic media.

Overall, about two-thirds (66.2\%) of FSWs interacted with the police and $14.9 \%$ reported police arrest (table 2). About three-fourths $(77.9 \%)$ of FSWs who had ever interacted with the police perceived that the behaviour of the police was better than the previous year. All the indicators shown in table 2 varied significantly across the districts. For example, while about $59.0 \%$ of FSWs in Medak and Khammam reported better treatment by the police, this percentage was as high as $76.6 \%$ in Warangal and $83.3 \%$ in Ananthapur $(\mathrm{p}<0.001)$.

Results in table 3 indicate that the presence of active CAGs had a significant effect in increasing the number of FSWs who have been linked to ration cards, bank accounts and health insurance in the year preceding the survey. For example, the mean number of FSWs who received ration cards in PSUs with active CAGs was 12.8 as compared with 6.8 in PSUs with non-active CAGs $(\beta=6.2 ; \mathrm{SE}=1.7 ; \mathrm{p}<0.001)$. Similarly, PSUs with active CAGs, compared with those with non-active CAGs, had a significantly higher mean number of FSWs who were linked to bank accounts (5.9 vs 9.3; $\beta=3.4 ; \mathrm{SE}=1.6 ; \mathrm{p}=0.05$ ) and health insurance (13.1 vs $7.0 ; \beta=6.3 ; S E=2.4 ; p=0.02$ ).

Table 4 presents the association between CAG status and duration of acquisition of different social entitlements. A smaller proportion of FSWs belonging to PSUs with active CAGs as compared with those from other PSUs reported acquisition for more than 36 months of a ration card $(80.1 \%$ vs $89.6 \%, p<0.01)$, bank account $(12.8 \%$ vs $19.5 \%, \mathrm{p}=0.06)$ and enrolment of children in the free educational system $(51.5 \%$ vs $61.2 \%, \mathrm{p}=0.04)$. A little more than one-tenth (10.8\%) of FSWs from PSUs with active CAGs had received a ration card within the past 36 months, whereas this percentage was $2.7 \%$ for FSWs belonging to PSUs without active CAGs $(p<0.01)$.

Table 5 shows the association between the presence of active CAGs and police behaviour with FSWs. In PSUs with active CAGs compared with their counterparts, the police were significantly more likely to explain the reasons for arrest $(95.7 \%$ vs $87 \%$; adjusted OR: $2.9,95 \%$ CI 1.2 to 6.9 ). FSWs belonging to PSUs with active CAGs were significantly more likely to interact with the police than others $(68.0 \%$ vs $59.6 \%$; adjusted OR: 1.5 , $95 \%$ CI 1.2 to 1.9). A higher proportion of FSWs from PSUs with active CAGs than their counterparts perceived that the police treated them more fairly now than a year before $(79.7 \%$ vs $70.3 \%$; adjusted OR: $1.7,95 \%$ CI 1.2 to 2.3 ).

\section{DISCUSSION}

The present study highlights the lessons learnt from the setting up of a CAG system, which is part of a scaled-up community

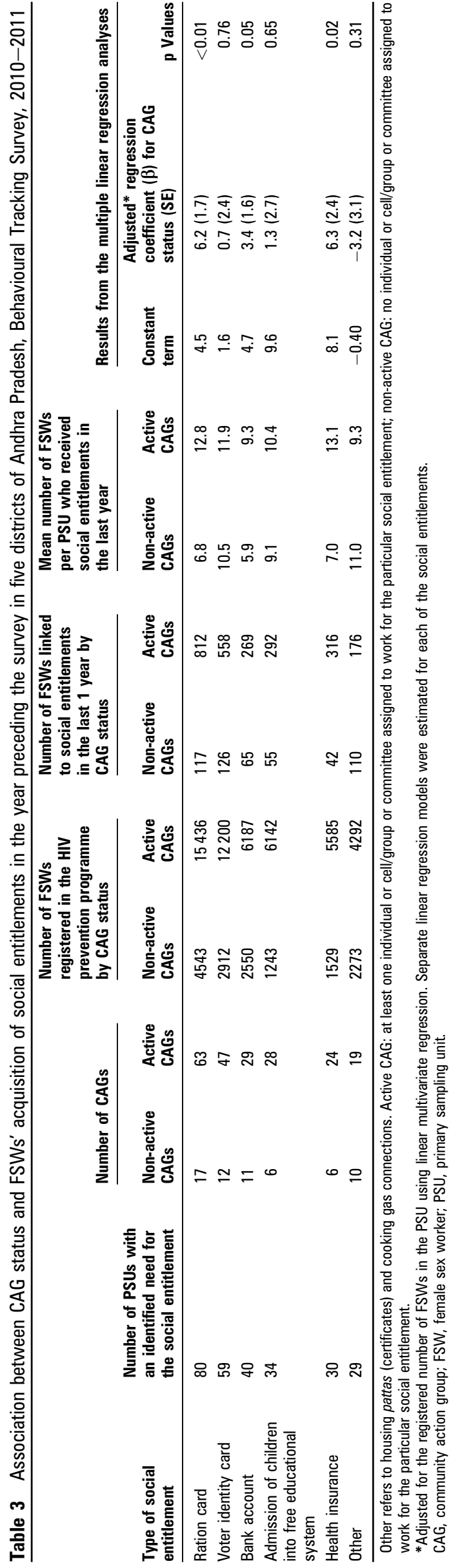




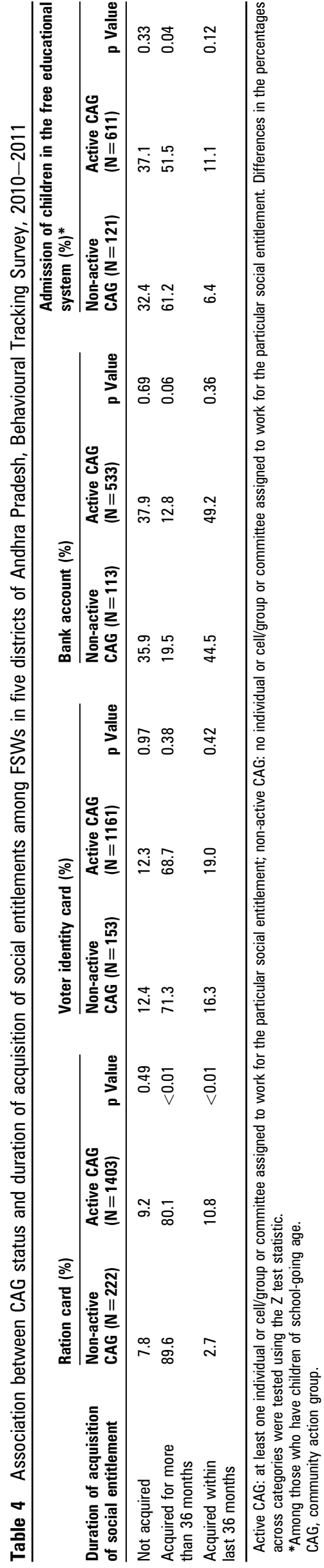

mobilisation strategy where individual FSWs in the intervention districts were facilitated to acquire social entitlements and the efforts were done to sensitise police behaviour. Although the system was established uniformly across the intervention districts around the same time, there were some sites where the CAG system was active and others where the CAG was not active at the time of the survey. The results of the survey suggest that a larger number of FSWs belonging to areas where CAGs were active received ration cards, bank accounts and health insurance as compared with FSWs in areas where CAGs were not active. Similarly, a larger percentage of FSWs from areas where CAGs were active perceived fair treatment by the police and perceived that the police explains the reasons for arrest (if they were arrested) as compared with FSWs in areas where CAGs were not active. The findings of this paper are similar to reports from other programmes in Andhra Pradesh as well as the qualitative materials of programmes in Karnataka, which show the positive effects of advocacy, one of the components of the community mobilisation programme (L Ramachandar, unpublished, 2011). ${ }^{6} 19$

The communities identified ration cards as the most needed social benefit, whereas lower priority was given to entitlements that have long-term benefits such as enrolment of children in the free education system and health insurance. This preference can perhaps be attributed to poverty and the community's immediate need for essential commodities. The CAGs facilitated several interactions between marginalised groups such as FSWs and those who wield power, such as the police. Facilitating such interactions and establishing communications between these two groups was an essential step to make the police understand the problems that FSWs face in a particular social, cultural, political and legal milieu. The survey data support this hypothesis and more positive response from the police in areas with active CAGs as compared with others. These findings highlight the need to initiate special advocacy measures within HIV prevention programmes, which include strategies to work with administrative agencies like the police and municipal corporations and agencies like banks and educational institutions to create an enabling environment for the sex worker community.

In addition to the quantitative data presented in this paper, several 'success stories' based on the activities of the CAG system have been presented in the news media. ${ }^{28}$ These narratives show that ongoing advocacy efforts and the principle of 'strength in numbers,' coupled with FSWs' sound knowledge of legal matters, are often key factors in advocacy encounters. For instance, in Khammam district of Andhra Pradesh, CAG leaders took a batch of FSWs' applications for ration cards and voter identity cards to the appropriate government offices and made a number of follow-up visits to these officials. Following ongoing pressure, after two months, the ration cards and voter identity cards were issued to all the members who had applied.

Although CAG members made persistent efforts to sensitise the police during the initial intervention period, the frequent transfers of sensitised police staff within and outside the implementation districts was a challenge as CAG members would have to restart the process of sensitising new incumbents each time new staff were posted. To address this issue, CAG members began organising 'thanksgiving parties' for sensitised staff, where community members as well as new incumbents were invited. These parties provided a platform for new incumbents to be sensitised by their own colleagues.

While this paper provides evidence of the effect of the CAG system on the community mobilisation programme, the results 
Table 5 Association between the presence of any active CAG and behaviour of the police with FSWs in five districts of Andhra Pradesh, Behavioural Tracking Survey, 2010-2011

\begin{tabular}{|c|c|c|c|}
\hline \multirow[b]{2}{*}{ Police behaviour } & \multicolumn{3}{|c|}{ Any active CAG } \\
\hline & No $(\mathrm{N}=781)$ & Yes $(N=1205)$ & Adjusted OR (95\% CI) \\
\hline Ever arrested by the police (\%) & 14.4 & 15.0 & $1.1(0.8$ to 1.4$)$ \\
\hline Police explained reasons for arrest* $(\%)$ & 87.0 & 95.7 & $3.2(1.1$ to 8.9$)$ \\
\hline Police informed at least one friend or relative about the arrest* $(\%)$ & 31.4 & 48.1 & $1.8(0.9$ to 3.7$)$ \\
\hline Ever interacted with the police (\%) & 59.6 & 68.0 & $1.5(1.2$ to 1.9$)$ \\
\hline Feel that the police treat FSWs more fairly now than they did a year before $\dagger(\%)$ & 70.3 & 79.7 & $1.7(1.2$ to 2.3$)$ \\
\hline
\end{tabular}

Any active CAG: at least one individual or cell/group or committee assigned to work for any of the following social entitlements: ration card, voter card, bank account, free education for children and health insurance. PSU without any active CAG were considered as reference group.

ORs were adjusted for the following socio-demographic characteristics of FSWs: current age (entered as continuous variable), any formal schooling (no, yes), marital status (currently married not currently married), typology of sex work (home based, street based, brothel based) and duration of sex work (entered as continuous variable) using logistic regression.

*Among FSWs who had ever been arrested. It refers to FSWs' experience when they were arrested last time.

†Among FSWs who had ever interacted with police.

CAG, community action group; FSW, female sex worker; PSU, primary sampling unit.

of this study must be interpreted cautiously due to several limitations. This study does not present a full-scale evaluation of the CAG system, rather it aimed to provide a description of the CAG system and demonstrate its benefits for FSWs. Moreover, the areas without an active CAG did not represent a 'true control area' due to several reasons. First, both areas with active CAGs and those without active CAGs had identical community mobilisation programmes. Second, advocacy with powerful state actors at the district level may have benefited even those areas within the district that do not have an active CAG. Third, FSWs are often mobile, and some of those who were interviewed might have moved from areas with active CAGs to areas without active CAGs or vice versa; such unrecorded intra- and inter-district mobility is likely to have confounded the comparison. Finally, although this study establishes the significant positive benefit of the presence of active CAGs for marginalised communities in terms of increasing FSWs' access to social entitlements, little has been achieved by CAGs in the programme. Some of the social entitlements (eg, free education for FSWs' children, bank accounts, health insurance) still appear to be out of reach for a substantial proportion of sex workers even in the presence of active CAGs. These results highlight the need for further research on the reasons for the inability of CAGs

\section{What is already known on this subject}

- HIV prevention interventions with FSWs highlight the need for a structural system to address violence and crisis situations in sex work settings.

- A few published programmatic research studies, which have mainly been conducted in brothel-based settings, show that incidents of violence reduce with the collectivisation of FSWs.

\section{What this study adds}

- Describes the process of developing CAGs in a setting where the majority of FSWs solicit clients from the non-brothel areas.

- Describes differences in sex workers' access to social benefits and enabling environment in the presence and absence of active CAGs. to advocate access to certain social entitlements for FSWs and the underlying response mechanisms from civil society and government organisations to the efforts of CAGs.

In conclusion, our study findings suggest that community mobilisation programmes to influence structural-level issues may require a specialised and dedicated advocacy group to improve community well-being and reduce the potential vulnerability of marginalised groups to abuse by several stakeholders including state administrative agencies. Given that the active CAG system had increased FSWs' acquisition of social benefits, programmes that include CAG systems need to ensure their active engagement in the programme and continuous dialogue between the community and stakeholders. Since HIV prevention interventions need to go beyond the promotion of safe sex behaviour, further attention is needed to develop community advocacy systems and strengthen existing CAGs to prevent abuse and protect the rights of marginalised communities.

Acknowledgements This paper was written as part of a mentorship programme under the Knowledge Network project of the Population Council, which is a grantee of the Bill \& Melinda Gates Foundation through Avahan, its India AIDS Initiative.

Contributors SP and RSP led the study design, conception and drafted the manuscript. RMM conducted the analyses and assisted with manuscript writing. PS BPM and SBK participated in the design of the study and assisted with interpretation of study findings. PP provided overall guidance with analytical approach, manuscript writing and interpretation of study findings. All authors read and approved the final manuscript.

Funding Support for programme implementation was provided to the India AIDS Alliance via a grant from the Bill \& Melinda Gates Foundation through Avahan, the India AIDS Initiative. The views expressed herein are those of the authors and do not necessarily reflect the official policy or position of the Bill \& Melinda Gates Foundation and Avahan

\section{Competing interests None.}

Ethics approval Ethical committee of Family Health International and the Karnataka Health Promotion Trust.

Provenance and peer review Commissioned; externally peer reviewed.

\section{REFERENCES}

1. National AIDS Control Organization. Press Release: HIV declining in India; New infections reduced by 50\% from 2000-2009; Sustained Focus on Prevention Required. New Delhi: Ministry of Health \& Family Welfare, Government of India, 2010.

2. National AIDS Control Organization (NACO). NACP-III: To Halt and Reverse the HIV Epidemic in India. New Delhi: India Ministry of Health \& Family Welfare, Government of India, 2006

3. UNAIDS. Report on the Global AIDS Epidemic. 2008. http://www.unaids.org/en/ dataanalysis/epidemiology/2008reportontheglobalaidsepidemic/ (accessed 2 Aug 2011).

4. National AIDS Control Organization (NACO). National Behavioral Surveillance Survey, 2006, Female Sex Workers and Clients of Female Sex Workers. New Delhi: Ministry of health \& Family Welfare, Government of India, 2006. 
5. Panchanadeswaran S, Johnson SC, Sivaram S, et al. A descriptive profile of abused female sex workers in India. J Health Popul Nutr 2010; 28:211-20.

6. Argento E, Reza-Paul S, Lorway R, et al. Confronting structural violence in sex work: lessons from a community-led HIV prevention project in Mysore, India. AIDS care 2011;23:69-74.

7. Beattie T, Bhattacharjee $P$, Ramesh B, et al. Violence against female sex workers in Karnataka state, south India: impact on health, and reductions in violence following an intervention program. BMC Public Health 2010:10:476.

8. Blankenship K, Friedman S, Dworkin S, et al. Structural interventions: concepts, challenges and opportunities for research. J Urban Health 2006;83:59-72.

9. Jana S, Basu I, Rotheram-Borus MJ, et al. The Sonagachi Project: a sustainable community intervention program. AIDS Educ Prev 2004;16:405-14.

10. Reed E, Gupta J, Biradavolu M, et al. The context of economic insecurity and its relation to violence and risk factors for HIV among female sex workers in Andhra Pradesh, India. Public Health Rep 2010;125(Suppl 4):81-9.

11. Swendeman D, Basu I, Das S, et al. Empowering sex workers in India to reduce vulnerability to HIV and sexually transmitted diseases. Soc Sci Med 2009;69:1157-66.

12. Reed E, Gupta J, Biradavolu M, et al. The role of housing in determining HIV risk among female sex workers in Andhra Pradesh, India: considering women's life contexts. Soc Sci Med 2011;72:710-16.

13. Miller CJ, Shattock RJ. Target cells in vaginal HIV transmission. Microbes Infect 2003:5:59-67.

14. Rachakulla HK, Kodavalla V, Rajkumar $\mathrm{H}$, et al. Condom use and prevalence of syphilis and HIV among female sex workers in Andhra Pradesh, India-following a large-scale HIV prevention intervention. BMC Public Health 2011:11(Suppl 6):S1.

15. Blankenship KM, Bray SJ, Merson MH. Structural interventions in public health. AIDS 2000;14(Suppl 1):S11-21.

16. de Souza R. Creating "communicative spaces": a case of NGO community organizing for HIV/AIDS prevention. Health Commun 2009;24:692-702.

17. Halli SS, Ramesh BM, O'Neil J, et al. The role of collectives in STI and HIV/AIDS prevention among female sex workers in Karnataka, India. AIDS care 2006;18:739-49.
18. Chattopadhyay A, McKaig RG. Social development of commercial sex workers in India: an essential step in HIV/AIDS prevention. AIDS Patient Care STDS 2004:18:159-68

19. Biradavolu MR, Burris S, George A, et al. Can sex workers regulate police? Learning from an HIV prevention project for sex workers in southern India. Soc Sci Med 2009:68:1541-7.

20. Celentano DD, Nelson KE, Lyles CM, et al. Decreasing incidence of HIV and sexually transmitted diseases in young Thai men: evidence for success of the HIV/AIDS control and prevention program. AIDS 1998:12:F29-36.

21. Nag M. Sex workers in Sonagachi: Pioneers of a revolution. Eco Politic Wkly 2005; $\mathbf{4 0 : 5 1 5 1 - 6}$

22. Chakraborty AK, Jana S, Das A, et al. Community based survey of STD/HIV infection among commercial sexworkers in Calcutta (India). Part I. Some social features of commercial sexworkers. J Commun Dis 1994;26:161-7.

23. Galavotti C, Wheeler T, Kuhlmann AS, et al. Navigating the swampy lowland: a framework for evaluating the effect of community mobilization in female sex workers in Avahan, the India AIDS Initiative. J Epidemiol Community Health 2012:66:ii9-ii15.

24. Wheeler T, Kiran U, Jayram M. Live and Learn: Reflections on participation and community mobilization through the implementation of the Avahan HIV/AIDS Initiative in India. J Epidemiol Community Health 2012;66:ii16-ii25.

25. USAID. Social Capital and HIV Risk Behavior among Female Sex Workers and Men who have Sex with Men in Andhra Pradesh: Insights from Quantitative and Qualitative Data. 2006. http://www.odi.org.uk/resources/docs/1792.pdf laccessed 1 Jul 2011).

26. Samuels F, Pelto PJ, Verma R, et al. Social Capital and HIV Risk Behavior Among Female Sex Workers and Men Who Have Sex With Men in Andhra Pradesh: Insights from Quantitative and Qualitative data. Horizons Research Update. Washington DC: Population Council, 2006:3.

27. Saidel T, Adhikary R, Mainkar M, et al. Baseline integrated behavioural and biological assessment among most at-risk populations in six high-prevalence states of India: design and implementation challenges. AIDS 2008;22(Suppl 5):S17-34.

28. India HIV/AIDS Alliance. AP. Community Advocacy Efforts. http://allianceap.org/ media/community advocacy efforts media.htm (accessed Jan 2012). 